\title{
Kemandan Viyolaya Geçiş Aşamasinda Temel Yöntemler
}

\author{
Basic Methods in Transition from Violin to Viola
}

\author{
Banu YINALL ${ }^{1}$ (1)
}

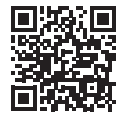

DOI: 10.26650/CONS2019-0015

'Dr. Öğr. Üyesi, Mimar Sinan Güzel Sanatlar Üniversitesi, İstanbul Devlet Konservatuvar Yaylı Çalgılar Anasant Dalı, Viyola Sanat Dalı, İstanbul, Türkiye

ORCID: B.Y. 0000-0002-0165-4386

\section{Sorumlu yazar/Corresponding author: Banu Yinal, \\ Mimar Sinan Güzel Sanatlar Üniversitesi İstanbul Devlet Konservatuvarı Yaylı Çalgılar Anasanat Dalı, Viyola Sanat Dalı, Vişnezade, Dolmabahçe Cad. 34357 Beşiktaş, İstanbul, Türkiye \\ E-posta/E-mail: banuyinal@hotmail.com}

Başvuru/Submitted: 02.11.2019 Revizyon Talebi/Revision Requested: 17.12.2019

Son Revizyon/Last Revision Received:

19.12.2019

Kabul/Accepted: 27.12 .2019

Atıf/Citation: Yinal, B. (2019). Kemandan viyolaya geçiş aşamasinda temel yöntemler. Konservatoryum - Conservatorium, 6(2), 139-150. https://doi.org/10.26650/CONS2019-0015

\section{ÖZ}

Keman ve viyola yaylı çalgılar ailesinin birer üyesidir. Fiziki olarak birbirlerine benzeseler de sağ ve sol el teknik farklılıkları, anahtar kullanımı, ses rengi ve boyutları iki enstrümanı birbirinden ayıran unsurlardır. Viyolanın daha büyük bir enstrüman olmasından dolayı tutuş, sağ el ve sol el teknikleri kemana göre farklılık göstermektedir. Viyolaya geçiş sürecinde öncelikle çalgının tarihsel süreçteki gelişimi bilinmelidir. Daha sonra her iki çalgı arasındaki sağ el ve sol el teknik farklılıkları, tutuş, anahtar okuma, entonasyon, ton oluşturma, vibrato gibi temel çalışmaların yapılması öğrencinin uyum sürecini hızlandıracaktır. Bu çalışmada, geçiş döneminde birebir yaşanmış tecrübelere dayanarak oluşturulmuş yöntem ve öneriler çerçevesinde temel bilgiler ayrıntılı olarak ele alınmıştır. Çalışmanın amacı, keman ve viyolanın fiziksel benzerliklerine rağmen teknik farklılıklarına dikkat çekerek bilinçli bir geçiş sürecine yardımcı olmaktır. Araştırmada konu ile ilgili basıımış ve internet ortamında yayınlanmış kaynaklar incelenmiş ve kullanılmıştır. Geçiş sürecini yaşayan öğrencilere her iki çalgı arasındaki farkıııkların aktarılması ve adapte sürecinin doğru ve bilinçli bir şekilde tamamlanması için oluşturulmuş öneriler kullanılarak öğrencilere rehberlik edilmesi gerekmektedir.

Anahtar Kelimeler: Keman, Enstrüman Geçişi, Viyola

\section{ABSTRACT}

The violin and viola belong to the string instruments family. Although physically similar, the two are distinguishable because of right- and left-hand technical differences, key usage, sound color, and size. The viola has a larger grip, and its right- and left-hand techniques differ from the violin. When converting a department from violin to viola, it is important to learn the historical process in the development of the instrument. Then, the basic knowledge and practicessuch as the technical differences between right and left hands, holding, key reading, intonation, tone production, and vibrato-would accelerate students' adaptation process. In this study, basic technical information-except the methods and suggestions based on the author's personal experiences and those during the transition process-are discussed in detail. The study aims to focus on the technical differences between the viola and violin despite their physical similarities. Printed and online sources have been used and analyzed in this study. Students must be guided using the suggestions created to convey the differences between the instruments to those transitioning to complete the adaptation process accurately and consciously.

Keywords: Violin, Instrument Transition, Viola 


\section{EXTENDED ABSTRACT}

The violin family reached its present form in the 17th and 18th centuries with the development process in history. The viola, a member of the violin family, was overshadowed with accompaniment pieces during the early periods. With the prominence of chamber music and orchestral works, the viola began to gain value, leading to solo compositions. Georg Philip Telemann composed the first viola concerto. The F Major Viola Concerto that was later composed by Carl Ditters von Dittersdorf, Johannes Christian Bach's Viola Concerto, and Karl Stamitz's Viola Concerto were also included in the viola repertoire. In the 20th century, the viola solo repertoire was composed by important composers of the period, namely Paul Hindemith, Bela Bartok, and William Walton.

After the viola attained a solo identity, viola artists began emerging. In addition to those who started their education with the viola, some artists started with the violin but continued with the viola. Recently, some artists who graduated from violin departments have gone on to be viola players in orchestras.

In this study, information is given to students who switch from violin to viola to ensure an easy and mindful transition process. The suggested methods and recommendations considering research and experiences are evaluated in seven headlines.

1- Differences between Violin and Viola

2- Instrument and Bow Selection

3- Grip

4- Reading the C Clef

5- Intonation

6- Obtaining a Quality Tone

7- Vibrato

\section{1- Differences between Violin and Viola}

The violin and viola differ in terms of size, length, strings, and clef. These lead to differences in grip and playing techniques for the two instruments. Violin, which has a soprano timber, is played using the treble clef, whereas viola, which has an alto timber, uses $\mathrm{C}$ clef. Considering its size, the viola has a different tone than the violin, with chords five notes lower and thicker strings. 


\section{2- Instrument and Bow Selection}

Viola selection should be made according to the student's hand and arm structure. To determine the viola's suitability to the arm structure, it is held in the playing position; the snail is grasped with the left palm, in which case the arm should be flat and comfortable. Handle thickness should be appropriate to the hand structure.

The choice in bow should be made according to the dimensions of the instrument.

\section{3- Grip}

There are differences in grip between the violin and viola. Since the viola is a larger and wider instrument, the arms must be distant from each other. The left arm should be more open than with the violin, and the wrist position should be kept at a wide angle. For the left-hand fingers to move freely on the touch, the viola's balance must be maintained, keeping the thumb free and straight without squeezing and ensuring it moves with the entire hand in position transitions. Since the viola bow is heavier than the violin's, the fingers must be kept in a slightly more open position.

\section{4- Key Reading}

While the violin is played with the treble clef, the viola is played with the C clef and treble clef on high pitches. Students transitioning from violin to viola experience the challenge of clef differences. For adapting to the clef in a short period, sight-reading should be practiced.

\section{5- Intonation}

Intonation is the most important stage of the transition process. For correct resonance of full tones, they should be pressed more mildly than with the violin. In this process, major-minor scales and arpeggios, as well as exercises selected from Schradieck and Sevcik methods, provide the basic studies for intonation.

\section{6- Obtaining a High-quality Tone}

For a qualified tone, balance at the resonance point is important. The speed and pressure must be balanced correctly. The weight of the right arm should be evenly distributed over the fingers. The softening of the string changes by wrist movements and the continuation 
of the weight given while pulling the string is vital in tone formation.

\section{7-Vibrato}

Vibrato is necessary for musical expression. A good tone needs consistent, uninterrupted vibrato. The speed and extent of the vibrato should be based on the musical characteristics of the performed piece.

\section{Conclusion}

For a smooth switch from violin to viola, students must know the differences between the two instruments. Due to the large size of the viola, differences in grip require rightand left-hand exercises. The study aims to help the transition process by highlighting the technical differences between the violin and viola despite their physical similarities. This research examined and utilized published and online resources on the subject. 


\section{Giriş}

Keman ailesinin ortaya çıkış yeri hakkında kesin bir bilgi bulunmamaktadır ancak teorilere göre İtalya'da doğmuştur. Modern kemanın atası sayılabilecek Viel, Rebec ve Lira de Braci gibi enstrümanlar günümüzde kullanılan kemana oldukça benzerdirler. Keman ailesinin gelişim sürecinde Viol adıyla anılan birçok tür ortaya çıkmıştır.

"Violler, Bacak Violleri (Viola da Gamba) ve Kol Violleri (Viele, Viola da Broccio) olarak ikiye ayrılmaktadır. 1250 -1535 yılları arasında Viele doğmuş ve Viele'den, Viola da Braccio, Viola d'Amour ve Viola da Gamba geliştirilmiştir. Viola da Braccio'nun gelişim sürecinde ince sesli olanına "Violino" diğerlerine "Viola" adı verilmiştir. Viola da Braccio, günümüz kemanı ve viyolanın atası olarak kabul edilmektedir" (Teomete, 1990, s. 28).

“Görüldüğü gibi kemanın gelişimi, 17. yy.' da büyük aşama kaydetmiştir. İtalya'da Gaspara da Salo, Andrea Amati, Antonio Stradivarius ve Giuzeppe Guarnerius gibi keman lütiyelerinin yaptığı kemanlarla değer kazanmıştır. Kemana verilen önem arttıkça dönemin bestecileri çok sayıda eser bestelemiştir" (Hüseyinova, 2007). Aynı dönemde keman ailesinin bir üyesi olan viyola, solo eserler yazılmadığı için eşlik partileri çalarak kemanın gölgesinde kalmıştır. 18. yy. sonları ise viyola için yeni bir dönemin başlangıcı olmuştur. Oda müziği ve orkestra eserlerinin daha fazla ön plana çıkmasıyla viyola önem kazanmaya başlamış devamında viyola için solo eserler bestelenmiştir. İlk viyola konçertosu 1716-1721 yılları arasında G. F. Telemann tarafından bestelenmiştir (Montgomery Philharmonic, 2015). Bununla birlikte, Carl Ditters von Dittersdorf - Fa Majör Konçerto, Johannes Christian Bach - Do Minör Viyola Konçertosu, Karl Stamitz - Re Majör Konçerto viyola repertuvarının önemli eserleri arasında yer almaktadır. 20. yy.'da solo viyola repertuvarı dönemin bestecileri tarafindan oldukça zenginleştirilmiştir. William Walton Viyola Konçertosu, Paul Hindemith Viyola ve Orkestra için Der Schwanendreher, Béla Bartók Viyola Konçertosu da viyola repertuvarının ve konservatuvar müfredatının önemli eserlerindendir. Böylece, viyolanın solo kimlik kazanmasıyla birlikte daha fazla viyola sanatçısı yetişmeye başlamıştır. Eğitimine viyola ile başlayanlar olduğu gibi kemandan viyolaya geçiş yapan öğrenciler de bulunmaktadır. Bu öğrencilerin viyolaya geçmelerinde fiziksel yatkınlığın önemli bir rolü olduğu gibi viyolanın solo çalgı olarak değer kazanmaya başlamış olmasının da payı büyüktür.

$\mathrm{Bu}$ çalı̧̧mada, eğitmenler tarafından viyolaya geçişi uygun bulunan öğrencilerin uyum sürecini sorunsuz bir şekilde gerçekleştirmesi amaçlanarak; araştırmalar ve ya- 
şanmış tecrübeler 1şığında ortaya konan yöntem ve öneriler 7 madde olarak ele alınmıştır.

1. Keman ve Viyola Arasındaki Farklilıklar

2. Enstrüman ve Yay Seçimi

3. Tutuş

4. Anahtar Okuma

5. Entonasyon

6. Kaliteli Bir Ton Elde Etme

7. Vibrato

\section{Keman ve Viyola Arasındaki Farklılıklar}

Tarihsel süreçte keman ve viyola arasında büyüklük, uzunluk, tel seçimi, anahtar gibi farkl11ıklar oluşmuştur. $\mathrm{Bu}$ da iki enstrüman arasında tutuş ve çalış tekniklerinde farkl1laşmaya sebep olmaktadır. Soprano ses alanına sahip kemana oranla 7-8 $\mathrm{cm}$ daha büyük olan viyola, alto ses alanına sahiptir. Kemanda Mi-La-Re-Sol, viyolada La-Re-Sol-Do telleri kullanılır. La-Re-Sol telleri her iki enstrümanın ortak telleridir ancak viyolanın büyüklüğü ve tellerinin kalınlığından dolayı viyola farklı bir tona sahiptir. Viyolanın ses aralıkları kemana göre yaklaşık bir buçuk milimetre daha büyüktür. Bu da aralıkların kemana göre daha açık basılmasını gerektirir. Soprano ses alanına sahip olan keman notaları sol anahtarıyla; alto ses alanındaki viyola notaları üçüncü çizgi do anahtarı ve tiz seslerde sol anahtarı ile yazılır. Bu anahtar farkı viyolaya geçen öğrenciler için alışma sürecinde zorlayıcı olabilir. Kolay seviye etütleriyle yapılacak okuma ve çalma çalışmaları faydalı olacaktır.

Yaylı çalgılar içinde solo enstrüman olan keman için çok sayıda eser yazılmıştır. Kemanın gölgesinde kalan viyola için az sayıda eser yazıldığından kemandan ve farklı enstrümanlardan düzenleme yapılarak viyola repertuvarı genişletilmiştir. Ancak, 20. yüzyılda P. Hindemith ve B. Bartók gibi değerli bestecilerin eserleri viyola repertuvarını zenginleştirmiştir. Repertuvarın zenginleştirilmesinin yanı sıra, senfoni ve oda müziği eserlerinde de keman ve viyola arasında farklılıklar görülmektedir. En basit haliyle bir orkestra düzeninde Kemanlar, 1. ve 2. Keman olarak iki gruba ayrilırken viyola, tek gruptan oluşmaktadır. Bununla birlikte keman ve viyola arasındaki farklılıklar sadece eser üretimi, çalma tekniği veya enstrümanların doğal yapısı ile sınırlı kalmamaktadır. Keman ve viyola arasındaki farklardan biri de tutuş tekniğidir. Birtakım düzenlemeleri içeren tutuş, 
yay kolunun daha fazla açılması, sol el ve kol pozisyonunun ayarlanması ile başlar. Bir kemancının viyolayı keman gibi çalması ender rastlanan bir durum değildir, ancak viyolaya geçen öğrencinin her iki enstrümanın inceliklerini bilmeden çalması sorunlara yol açacaktır. Eğer viyola, keman tekniği ile çalınırsa sol el tutuş ve parmak aralıkları farkından dolayı entonasyon sorunları da beraberinde gelecektir. Sağ el tutuş farklılıklarından dolayı viyola tonu elde etmekte zorlanılabilir (Watts, 2014).

\section{Enstrüman ve Yay Seçimi}

Viyola, tarihsel süreçte değişimlere uğramıştır. Lionel Tertis, Paul Hindemith ve çalg1 yapımcısı Arthur Richardson modern viyolanın oluşumunda önemli rol oynamışlardır. L. Tertis, 1937 modeli için "gördüğüm, duyduğum ve çaldığım birçok enstrüman içinde, bu model eski ustaların tüm iyi noktalarının birleştiği ve viyolanın büyük boyut sorunlarının ortadan kalktığı bir enstrümandır” (Watts, 2014, s. 5) yorumunu yapmıştır.

"Viyola kemandan daha büyük ve uzun bir çalgıdır. Bir tam kemanın uzunluğu 35,5 iken, bu uzunluk viyolada 38 cm'den 42 cm'ye kadar çıkabilmektedir. Çok yaygın olmasa da $42 \mathrm{~cm}$ 'den daha büyük viyolalara da rastlanmaktadır. Bir viyola yayının ağırlığı 69-74 gr ağırlığındayken, keman yayı ortalama 10 gram daha hafiftir. Keman ve viyola yayı topuğun şekline bakarak ayırt edilebilir, keman yayının topuğu köşeli ve sivri iken, viyola yayının topuğu genellikle yuvarlatılmıştır” (Çalgan, 2015, s. 3).

Viyolaya geçen öğrencinin çalgıyı rahat tutabilmesi, pozisyon değişimlerinde çalgıya hâkim olabilmesi için el ve kol yapısına uygun büyüklükte çalgı seçimi yapılmalıdır. Viyolanın kol yapısına olan uygunluğunu anlamak için viyola çalar pozisyonda tutulur ve sol el avuç içi salyangozu kavrayacak biçimde uzatıllr. Bu durumda sol kol düz ve rahat olmalıdır. Çalgının sap kalınlığı el yapısına uygun olmalıdır. İnce ellere sahip bir ögrencinin kalın saplı viyola ile çalması teknik zorluklara sebep olabilmektedir. Yay seçimi, çalgıdan elde edilecek ses kalitesine göre belirlenmelidir. Buna göre çalgının boyutlarına uygun ağırlıkta yay kullanılmalıdır. Andonov'a göre, "Gövde uzunluğu $38 \mathrm{~cm}$ olan çalgılar için $68 \mathrm{gr}, 40 \mathrm{~cm}$ için $71 \mathrm{gr}, 43 \mathrm{~cm}$ için ise yay ağırlı̆̆ $74-75$ gr'dan az olmamalıdır" (aktaran Hakioğlu, 2018, s. 433). 
Tablo 1: Ortalama Keman, Viyola ve Yayların Oran Farkl11ıkları (Watts, 2014, s. 6)

\begin{tabular}{|l|l|l|}
\hline Genel Ölçüler & Keman & Viyola \\
\hline Uzunluk & $35,56 \mathrm{~cm}$ & $41,656 \mathrm{~cm}$ \\
\hline Yükseklik & $3,175 \mathrm{~cm}$ & $3,81 \mathrm{~cm}$ \\
\hline Omuz genişliği & $16,764 \mathrm{~cm}$ & $20,32 \mathrm{~cm}$ \\
\hline Orta alan genişliği & $11,176 \mathrm{~cm}$ & $14,478 \mathrm{~cm}$ \\
\hline Alt alan genişliği & $20,828 \mathrm{~cm}$ & $25,146 \mathrm{~cm}$ \\
\hline Köprü bağı & $16,764 \mathrm{~cm}$ & $19,558 \mathrm{~cm}$ \\
\hline Sap genişliği & $3,556 \mathrm{~cm}$ & $5,08 \mathrm{~cm}$ \\
\hline Köprüde tel aralıkları & $3,556 \mathrm{~cm}$ & $4,064 \mathrm{~cm}$ \\
\hline Tuşe ile tel arasındaki yükseklik & $6 \mathrm{~mm}$ & $8 \mathrm{~mm}$ \\
\hline Tuşe uzunluğu & $27,432 \mathrm{~cm}$ & $32,004 \mathrm{~cm}$ \\
\hline Çalgı ağırlı̆̆ı & $15,36 \mathrm{gr}$ & $21,71 \mathrm{gr}$ \\
\hline Tel uzunluğu & $33,02 \mathrm{~cm}$ & $38,354 \mathrm{~cm}$ \\
\hline Ortalama Ölçüler & Keman Yayı & Viyola Yayı \\
\hline Ağırlık & $60,1 \mathrm{gr}$ & $69,3 \mathrm{gr}$ \\
\hline Uzunluk & $74 \mathrm{~cm}$ & $74,3 \mathrm{~cm}$ \\
\hline Topuk Ölçüsü & $2,7 \mathrm{~cm}$ & $3 \mathrm{~cm}$ \\
\hline
\end{tabular}

\section{Tutuş}

Sağ el, sol el teknikleri her iki enstrümanda benzerlik gösterse de viyolanın sağ el ve sol el tutuş pozisyonu ile ses aralıklarına basış mesafesi farklılık göstermektedir. Kemanda sol el parmakları yuvarlak ve yakın, sol kol tellere eşit açıda tutulmalıdır. Viyola daha büyük ve geniş bir çalgı olduğundan kolların birbirinden uzak olması gerekir. Sol kol kemana göre daha açık durmalı, bilek geniş açılı tutulmalıdır. Parmaklar, 1. ve 2. pozisyonlarda aralıkların üst pozisyonlara göre daha geniş olmasından dolayı daha açık basılmalıdır. Viyolada sol el parmaklarının tuşe üzerinde rahat hareket edebilmesi için viyolanın dengeli tutulması gerekmektedir. Hakioğlu, Berlyançik ve Masçenko’nun bu konudaki görüşlerine yer vermektedir: "Doğru bir tutuş alışkanlığı oluşturulması, çalg1 ağırlığının dört dayanak noktası arasında dağılması gerekliliğinin doğru algılanması ve anlaşılmasına bağlıdır. Dört dayanak noktası şöyledir: 1. Köprücük Kemiği; 2. Omuz Eklem Bölgesi (Köprünün Sol Ucu); 3. Gögüs Bölgesi (Köprünün Sağ Ucu); 4. Alt Çenenin Sol Tarafi” (Hakioğlu, 2018). Viyola sapının kemana oranla daha geniş olması, başparmağın çalınan pozisyona ve tele göre çalgının altına doğru alınmasını gerektirir. Tabea Zimmermann, "Viyolada sol el, her pozisyonda ikinci parmak merkezli olmalıdır, aksi halde dördüncü parmak uzun bir yoldan geçmek zorunda kalacaktır. Birinci parmağ1 uzatmak daha iyidir" (Solare, 2003) der. 
Watts'a göre başparmağın düz ve serbest olması diğer parmakların rahat hareket etmesini sağlamaktadır. Başparmağın sıkarak tutulması, pozisyon geçişleri, entonasyon ve vibrato için kısıtlayıcı bir durum oluşturur. Başparmak serbest şekilde pozisyon geçişlerde tüm el ile birlikte hareket etmeli, geride kalmamalıdır. Viyolanın çene ile omuz arasında kaymadan tutulması, sol elin kasılmadan daha rahat hareket etmesinde önemli rol oynamaktadır. Keman ve viyola arasındaki yapısal farklılıklar sebebiyle, öğrenci üst vücut kullanımındaki değişikliklere uyum sağlamalıdır (Watts, 2014). Viyolanın dik tutulması, yay hakimiyetine ve sol elin akıcı hareketine destek olmaktadır. Viyolanın rahat tutulması için doğru çenelik seçimi yapılmalıdır. Kısa boyunlu bir öğrencinin yüksek çenelik ve yüksek yastık kullanması boyun bölgesinde deformasyona sebep olabilir. Yastık gerekmedikçe kullanılmamalı, çenelik uygun yükseklikte seçilmelidir. Başlangıç aşamasında edinilen doğru tutuş, teknik ve müzikalitenin gelişiminini olumlu yönde etkilemektedir.

Keman yayına göre daha ağır olan viyola yayını daha açık pozisyonda tutmak gerekir. Nitelikli bir ton elde etmek için yay üzerinde ağırlığın dengelenmesi sağ el tutuşu ve kol ağırlığı ile ilgilidir. Yay üstündeki her parmağın ağılık merkezinde görevi vardır. Tüm parmaklar yay üzerinde doğal olarak kıvrılmalıdır. Yay; başparmak, orta parmak ve yüzük parmağı tarafından tutulur. İşaret parmağı ve küçük parmağın görevi yayın basıncını ve dengesini sağlamaktır. Yayın üç bölümü olan alt yarı, orta ve üst yarıda kısa yay çalışmaları yapılması önerilir.

Yayın hızı, teller üstündeki basınç ve köprüye olan mesafe sağ el kullanımı için temel unsurlardır. Yay üstündeki baskıyı doğru kurmak için yay, işaret parmağının orta ekleminin biraz altından tutulmalıdır ve orta parmak ile yüzük parmağı ise bitişik olarak topuğa doğru indirilmelidir. Küçük parmak yayın dengesini sağladığı için, yuvarlak bir şekilde durmalıdır. Bu şekilde parmaklar arasındaki denge, ses kalitesini etkilemektedir. Bazı öğrenciler küçük parmağını havaya kaldırdığında yayın bu yüzden denge kaybına uğradığı ve tuşeye doğru kaydığı gözlemlenmiştir. Kaliteli bir ton elde etmenin ilk adımı doğru tutuştur. Sol el ve sağ el tutuşlarının doğru oturması, teknik ve fiziksel olumsuzlukların oluşmasını engellemektedir.

\section{Anahtar Okuma}

Viyola, alto ses alanında yer alır. Viyola partisi üçüncü çizgi do anahtarı ve tiz seslerde sol anahtarı ile yazılır. Viyola ile kemanın en önemli farlılıklarından biri anahtardır. 
Anahtar değişimi viyolaya geçen öğrencileri başlangıçta zorlamaktadır. Anahtara alışma süreci sonunda akıcı okuma sağlanmalıdır.

"Üçüncü çizgi do anahtarını akıcı okumayı öğrenmenin ilk adımı yeni bir el-göz koordinasyonu geliştirmek olmalıdır" (Wallace, 1993, s. 73). Konservatuvar solfej eğitiminde tüm anahtarları okumayı öğrenen öğrenciler bu sayede do anahtarına da hakimdirler. Diğer eğitim kurumlarındaki öğrenciler Fontain adlı solfej metodunu üçüncü çizgi do anahtarıyla okuma çalışmaları yapabilirler. Kolay seviyede viyola etütleri, gam, arpej ve deşifre çalışmaları anahtar okumayı akıcı hale getirmeye yardımcı olacaktır.

\section{Entonasyon}

Viyolada tam aralıkların çalınması için parmakların kemana göre biraz daha açık basılması gerekir. Yarım aralıklarda öğrencinin fiziksel yapısına göre parmakların yakınlığ değiş̧kenlik gösterebilir. Viyolaya alı̧̧ma sürecinde Kreutzer No. 2 etüdü üzerine bağlı, bağsız yay çalışmaları; majör, minör gam ve arpej çalışmaları; Scharadieck ve Sevcik metotlarından yapılacak egzersizler entonasyon için uygun çalışmalar olacaktır.

\section{Kaliteli Bir Ton Elde Etmek}

Ton, kişinin müzikal kimliğinin yansımasıdır. Özellikle vibrato yapımındaki farklılıklar ton üretimini kişiselleştirmiştir. İyi bir ton elde etmek için doğru tutuş, kol ağırlığı, sol el parmaklarının esnekliği ve vibrato yapımı bir bütünün parçalarıdır. Yayı doğru açılarda kullanmak, ses kalitesini ve ton oluşumunu olumlu bir şekilde etkilemektedir.

Wallace'a göre fiziksel ve teknik farkl111klarda eğitmen, öğrenciye iyi bir ton ve artikülasyon geliştirmeyi öğretmelidir. Tüm yaylı çalgılarda iyi bir ton çıkarmanın temelinde; yay hızı, baskısı ve ses çıkarma noktası arasında kurulacak ilişki yer alır. Viyolada bu üç unsur daha fazla denge gerektirir (Wallace, 1993). Viyola yayı keman yayına oranla daha ağır ve uzun olduğu için yayı tutan parmakların daha açık tutulması, koldan gelen ağırlığın parmaklar tarafından eşit olarak dağıtılmasına yardımcı olacaktır. Düzenli yapılan yay çalışmaları sağ kol ağırlığının etkin kullanılması için faydalıdır.

\section{Vibrato}

Vibrato, güzel bir ton ve müzikal ifade için vazgeçilmezdir. Vibrato, parmakların esnekliği sağlandıktan sonra kol, bilek ve parmak eklemlerinin eşit ve yoğun hareketiyle elde 
edilir. Ancak başlangıçta vibrato çalışmasının öğrenciye doğru aktarılması ve düzenli çalıştırılması son derece önemlidir, çünkü yanlış öğrenilen vibratoyu sonradan düzeltmek oldukça zordur. Viyolanın daha geniş bir enstrüman olmasından dolayı geniş vibrato yapma eğilimi olabilir ve sık vibrato elde etmek için farklı tempolarda vibrato çalı̧smaları yapmak faydalı olacaktır.

Kemana göre daha geniş vibrato yapılması boyut farkındandır, ancak vibratoyu hızı düşürmeden özellikle parmak eklemiyle desteklemek iyi bir ton elde edilmesine yardımc1 olmaktadır. Vibrato yaparken bir önceki parmak tuşe üzerinde tutularak (2. parmak vibrato yaparken 1. parmağın basılması gibi) vibrato yapan parmağa destek olunur ve bu şekilde vibratonun daha dengeli duyurulması amaçlanır. Vibrato, viyolanın kalınlığı ve uzunluğundan biraz etkilenmektedir. Wallace, viyolada kemana göre daha yavaş ve daha geniş vibrato yapma eğilimi olduğunu belirtir, ancak bu düşüncenin doğru olmadığını savunur. Buna bağlı olarak, vibrato hızı ve genişliği, çalınacak eserin müzikal özelliğine göre olmalıdır (Wallace, 1993).

\section{Sonuç}

Viyola günümüzde solo olarak sahnelerde yer alan bir çalgıdır. Yorumcu olarak etkili bir müzikaliteye sahip olmak için çalgıya teknik olarak hakim olmak gerekir. Sağ el ve sol elde doğru tutuş, entonasyon ve vibrato, nitelikli sonorite bu hakimiyeti sağlamanın en önemli gereklerindendir. Keman ve viyola arasında benzerlikler olmasına rağmen her iki çalgının kendine ait özellikleri vardır. Viyolanın daha büyük gövdeye ve daha kalın tellere sahip olması, çalgıdan ses elde etmek için farklı teknikler gerektirmektedir. Bu teknik yaklaşımlar yukarıda belirtilen başlıklar altında verilmiştir. Viyolaya geçiş sürecindeki öğrencinin çalgısına kolay uyum sağlaması için her iki çalgının benzerliklerine rağmen farklı tonlara ve farklı teknik özelliklere sahip olduğunu bilmesi gerekir. Nitelikli bir ton çıkarabilmek için sağ kol ağırlığının yaya aktarılması, yayın doğru tutulması ve yay hızının yanısıra; sol el ve sol kolun duruşu büyük önem taşımaktadır. Bu çalışmada, keman ve viyola arasındaki temel teknik farklılıklar ele alınmış, öğrenci ve öğretmenler için yol gösterici bilgiler vermesi amaçlanmıştır.

Finansal Destek: Yazar bu çalışma için finansal destek almamıştır. 


\section{Kaynakça}

Çalgan, G. (2015). Kemandan viyolaya geçiş süreci. Uludağ Üniversitesi Fen-Edebiyat Fakültesi Sosyal Bilimler Dergisi, 28(1), 1-9.

Hakioğlu, S. (2018). Viyola eğitiminde viyolaya özgü teknik yaklaşımlar. İdil Dergisi, 7(44), 429-434.

Hüseyinova, L. (2007). Tarihi gelişim sürecinde keman. Sosyal Bilimler Araştırmaları Dergisi, 2, $115-125$.

Montgomery Philharmonic. (2015). About Georg Philipp Telemann. Erişim adresi: https://montgomeryphilharmonic. org/page $86 /$ notes 9 b.html

Solare, K. M. (2003). Violist Tabea Zimmerman on technique, teaching and competitions. The Strad. Erişim adresi: https://www.thestrad.com/artists/violist-tabea-zimmermann-on-technique-teaching-and-competitions/6445. article

Teomete, Z. (1990). Viyola. (Yüksek Lisans Tezi). Marmara Üniversitesi Fen Bilimleri Enstitüsü, İstanbul.

Wallace, D. (1993). From violin to viola: Effecting a smooth transition. American String Teacher, 43, 71-74.

Watts, M. A. (2014). Making the switch: A physiological guide to mapping the transition from violin to viola. (Doctor of Musical Arts, University of Alabama, Tuscaloosa). Erişim adresi: http://acumen.lib.ua.edu/ u0015/0000001/0001765/u0015_0000001_0001765.pdf 